\title{
РАЗРАБОТКА И ИСПЫТАНИЕ ОБРАЗЦОВ РЕКОМБИНАНТНОЙ СУБЪЕДИНИЧНОЙ ВАКЦИНЫ ПРОТИВ КЛАССИЧЕСКОЙ ЧУМЫ СВИНЕЙ
}

\author{
К.П. АЛЕКСЕЕВ1, С.А. РАЕВ1, А.Г. ЮЖАКОВ1, Е.В. ШЕМЕЛЬКОВ1, \\ О.Е. ЛАТЫШЕВ1, О.В. ЕЛИСЕЕВА', Л.В. КОСТИНА', В.В. ЦИБЕЗОВ1, \\ В.В. СТАФФОРД 2 , К.Ю. КУНАКОВ ${ }^{1}$, О.А. ВЕРХОВСКИЙ ${ }^{3}$, \\ А.Д. ЗАБЕРЕЖНЫЙ 2 , Т.И. АЛИПЕР1
}

Классическая чума свиней (КЧС) - высококонтагиозное вирусное заболевание, продолжающее причинять значительный ущерб свиноводству во всех странах, входящих в десятку основных производителей свинины, за исключением США. Экономический ущерб обусловлен как вспышками заболевания, так и связанными с ними ограничениями в международной торговле. Природным резервуаром возбудителя служат дикие кабаны, которые представляют опасность для свиноводства в регионах с высокой плотностью их популяции. В России много десятилетий проводится поголовная вакцинация свиней живой аттенуированной вакциной. В настоящее время Россия выходит в число мировых лидеров по производству свинины, но для включения в глобальный рынок требуется получение статуса страны или отдельных ее регионов, свободных от вируса КЧС. Первым шагом может быть использование нереплицирующихся маркированных вакцин, позволяющих дифференцировать вакцинированных и переболевших животных. В этом сообщении мы впервые представляем результаты испытаний вакцинных препаратов на основе рекомбинантного белка Е2 вируса КЧС, позволившие выбрать схему введения, адъювант, дозировку специфического компонента. Предложен препарат, содержащий рекомбинантные белки Е2 вирусов КЧС генотипов 1 и 2, циркулирующих в настоящее время на территории Российской Федерации. Из испытанных образцов выбран безопасный и эффективный препарат, который после опытов по определению его стабильности и длительности посвакцинального иммунитета может быть рекомендован для клинических испытаний. Целью нашей работы было определение оптимального состава, дозы антигена и схемы применения вакцины на основе рекомбинантного поверхностного гликопротеина вируса КЧС Е2, отвечающей требованиям зоны, свободной от КЧС. В серии опытов на помесных поросятах (Sus scrofa, породы ландрас + дюрок, 84 гол., были разделены на 9 опытных и 2 контрольные группы) для контрольного заражения использовали высокопатогенный штамм-пробойник вируса КЧС Ши-Мынь в дозе $5 \times 10^{5}$ ЛД $_{50}$ из коллекции ФГБУ ВНИИЗЖ. Результаты наших исследований показывают, что дозы антигена 10 и 30 мкг при 2кратном введении вакцинного препарата, а также 30 и 60 мкг - при 1-кратном не обеспечивают достаточной степени защиты животных. Вакцины на основе масляного адъюванта (в отличие от синтетического полиакрилата) вызывали реактогенность в месте введения даже при 1-кратной вакцинации. Вакцинный препарат, содержащий 60 мкг антигена и синтетический полиакрилат в качестве адъюванта, при 2-кратном введении полностью защищал свиней от гибели после контрольного заражения, тогда как в контрольной группе невакцинированных и зараженных животных к 14-м сут после заражения 5 поросят из 11 пали. Лихорадка у вакцинированных животных протекала менее выражено и заканчивалась быстрее (подъем температуры был отсрочен на 2 сут, снижение лихорадки происходило на 2 сут раньше по сравнению с контролем заражения, p $\leq$ $0,05)$, частота и продолжительность виремии и выделения вируса достоверно $(p \leq 0,05)$ уменьшались по сравнению с показателями у невакцинированных особей. Кроме того, у животных из этой экспериментальной группы сохранялся ежесуточный прирост живой массы, лишь незначительно уступавший показателю в группе невакцинированных и незараженных поросят. В сыворотке крови вакцинированных животных перед контрольным заражением детектировалось высокое содержание антител к белку $\mathrm{E2}$ и не обнаруживались антитела к белку $\mathbf{E}^{\text {rns }}$. После перенесенной инфекции в крови животных появлялись антитела к белку $E^{\text {rns }}$. Таким образом, использование вакцины на основе синтетического полиакрилата, содержащего 60 мкг Е2 вКЧС, при 2-кратном применении позволяет получить высокую степень защиты после контрольного заражения. Кроме того, этот препарат может применяться как маркированная вакцина против КЧС.

Ключевые слова: классическая чума свиней, субъединичная вакцина, белок Е2, адъювант, разработка вакцины.

Классическая чума свиней (КЧС; Classical swine fever, CSV) - высококонтагиозная вирусная болезнь домашних и диких свиней, которая протекает в острой, хронической и субклинической формах и причиняет значительный экономический ущерб многим странам с развитым свиновод- 
ством (1-3). Так, в результате вспышек КЧС в 1993-1998 годах в ряде стран EC (Нидерланды, Германия, Испания, Бельгия, Италия) пришлось уничтожить более 13 млн свиней, а общий ущерб превысил 5 млрд евро (4).

Возбудителем болезни служит РНК-содержащий вирус, относящийся к роду Pestivirus семейства Flaviviridae. В этот же род входят вирусы диареи крупного рогатого скота I и II типов, а также вирус пограничной болезни (5). Геном вируса КЧС (вКЧС) представлен однонитевой молекулой РНК положительной полярности длиной 12,3 тыс. нуклеотидов, кодирующей четыре структурных и 8 неструктурных белков $(6,7)$. Вирионы вКЧС имеют форму сферических частиц диаметром 40-60 нм. Они состоят из нуклеокапсида и липопротеиновой оболочки. В состав нуклеокапсида входят РНК и белок С, оболочка образована тремя гликопротеинами $\mathrm{E}^{\mathrm{rns}}(\mathrm{gp} 44 / 48)$, E1 (gp33) и E2 (gp55), которые за счет дисульфидных связей образуют комплексы (E ${ }^{\mathrm{rns}}$ - гомодимер, E1-E2 - гетеродимер и E2 - гомодимер) (8). Белок $E^{\text {rns }}$ обладает рибонуклеазной активностью (9). Гетеродимерный комплекс E1-E2 обеспечивает проникновение вируса в клетку (10). На поверхности Е2 вКЧС находятся эпитопы, распознаваемые при клеточном и гуморальном иммунном ответе на вирус: моноклональные антитела к этому белку обладают вируснейтрализующей активностью (11, 12). Помимо антител к белку Е2, в организме инфицированных животных обнаруживают антитела к $E^{\text {rns }}$ и неструктурному белку NS3 (13).

Специфическая профилактика КЧС в России основана на применении безопасных и высокоиммуногенных живых вакцин. Наиболее эффективна вакцина КС, которая отличается от других аналогичных препаратов высоким содержанием вируса в одной прививной дозе (не менее $10^{5}$ ИмД ${ }_{50}$ (14). Однако классические живые вакцины не позволяют дифференцировать вакцинированных и инфицированных животных $(5,15$, 16). Эта проблема решается с помощью маркированных вакцин - субъединичных, химерных, векторных и ДНК-вакцин, из которых в качестве коммерческих препаратов доступна только субъединичная вакцина и лицензирована к применению химерная вакцина (15). Химерные вакцины по эффективности сопоставимы с традиционными живыми вакцинами (15, 16). Использование живых вакцин несет потенциальные риски рекомбинации вакцинного вируса с полевым и не всегда допустимо по правилам импорта продуктов животного происхождения, поэтому в качестве безопасной альтернативы живым вакцинам были разработаны субъединичные рекомбинантные вакцины на основе поверхностного гликопротеина Е2 вируса КЧС. Субъединичные вакцины вызывают менее продолжительный иммунитет, требуют больше времени для его формирования, вводятся 2-кратно, не обеспечивают стерильный иммунитет (16). Тем не менее они безопасны, обеспечивают защиту животных от контрольного заражения вирулентным вирусом и позволяют применять стратегию DIVA (differentiating infected from vaccinated animals - дифференциация инфицированных от вакцинированных животных) $(15,17,18)$. У вакцинированных свиней методом иммуноферментного анализа (ИФА) обнаруживают антитела только к белку Е2, а у инфицированных полевыми штаммами вируса КЧС животных - к белкам E ${ }^{\text {rns }}$ и E2 $(19,20)$.

Ранее нами был получен и охарактеризован рекомбинантный оболочечный белок Е2 штамма Ши-Мынь вируса КЧС (21) и на основе этого белка разработан лабораторный образец рекомбинантной субъединичной вакцины против КЧС, который защищал свиней от заражения вирулентным штаммом Ши-Мынь вируса КЧС (22). В настоящем исследовании мы усовершенствовали технологию получения рекомбинантного белка Е2 
вируса КЧС, создали конструкцию для коэкспрессии генов поверхностного гликопротеина Е2 двух генотипов вируса КЧС, циркулирующих на территории России, и определили состав и дозировку препарата, который безопасен и защищает экспериментальных животных от инфекции высокопатогенным штаммом-пробойником Ши-Мынь вируса КЧС.

Цель работы заключалась в определении оптимального состава, дозы рекомбинантного белка Е2 и схемы применения лабораторных образцов рекомбинантной субъединичной вакцины против классической чумы свиней.

Методика. Лабораторные образцы рекомбинантной субъединичной вакцины готовили из белка E2 штаммов 8Z, Ши-Мынь (генотип 1.1) и Альфорт-Тюбинген (генотип 2.3), полученных в бакуловирусной системе экспрессии генов в нашей лаборатории ранее. Последовательность, кодирующую эктодомен поверхностного гликопротеина Е2 вируса КЧС, амплифицировали с полевого материала (селезенка), поступившего в лабораторию в 1997 году. После определения первичной нуклеотидной последовательности амплифицированного фрагмента полевой изолят вируса КЧС (рабочее название 8Z) был отнесен к генотипу 1.1, как и штамм-пробойник Ши-Мынь (8Z отличается от последнего 8 аминокислотными заменами). Далее модифицировали коммерческий вектор pFastBacHTc («Life Technologies», США). По сайтам рестрикции CpoI и NcoI вырезали фрагмент между промотором и полилинкером плазмиды с закодированной гистидиновой меткой и сайтом узнавания TEV-протеазы и встраивали последовательность, кодирующую сигнальный пептид секреции токсина пчелиного яда мелиттина, которую собрали из трех синтетических олигонуклеотидов. C помощью праймеров, содержащих сайты рестрикции NheI и EcoRI, aмплифицировали часть последовательности гена E2 изолята 8Z (был исключен фрагмент, кодирующий 31-ю аминокислоту на С-конце белка, образующего трансмембранный домен). В результате экспресиии полученной конструкции наблюдали наработку секретируемого в культуральную среду эктодомена поверхностного гликопротеина Е2 изолята 8Z. Конструкция, несущая одновременно два гена, кодирующих поверхностные гликопротеины Е2 вирусов КЧС Ши-Мынь (генотип 1.1) и Альфорт-Тюбинген (генотип 2.3), получена синтетически («Евроген», Россия), оба гена предварены последовательностью сигнального пептида секреции мелиттина и тоже лишены участка, кодирующего трансмембранный домен. Трансфекцию клеток насекомых рекомбинантным бакуловирусным геномом, заражение клеток и накопление рекомбинантного белка в культуре клеток Sf-9 проводили согласно методике, описанной нами ранее (22). Кроме того, использовали коммерческий препарат рекомбинантного E2 («Prionics AG», Швейцария). В качестве адъювантов применяли синтетический полиакрилат (ООО «Ветбиохим», Россия), а также неполный адъювант Фрейнда («Sigma Aldrich», США). Полученные вакцины хранили при $4{ }^{\circ} \mathrm{C}$.

Эффективность различных вариантов рекомбинантной субъединичной вакцины против КЧС изучали на научно-исследовательской базе ФНЦ ВИЭВ РАН «Лисий остров» (г. Вышний Волочок). Для испытания использовали 84 поросенка 50-суточного возраста (получены из хозяйства, благополучного по КЧС, в котором проводится профилактическая иммунизация живой вакциной против КЧС). По результатам иммуноферментного анализа (ИФА), перед иммунизацией большинство поросят не содержали антител к вирусу КЧС. Животных распределяли по группам в зависимости от состава вакцины, содержания антигена и схемы вакцинации. Препараты (2 мл) вводили внутримышечно 1- или 2-кратно. При 
схеме с 2-кратным введением первую вакцинацию поросят проводили в 50-суточном возрасте, повторную - через 21 сут. При 1-кратном введении животных вакцинировали за 21 сут до контрольного заражения. Через 14 сут после второй вакцинации (либо через 21 сут после единственной вакцинации) животным во всех группах, за исключением X группы, интраназально и внутримышечно вводили по 2 мл штамма-пробойника Ши-Мынь $\left(1,25 \times 10^{5}\right.$ ЛД $50 /$ мл) (ФГБУ «ВНИИЗЖ», г. Владимир, Россия). Животных из Х группы (отрицательный контроль) перед заражением переводили в другое здание, чтобы исключить возможность случайного заражения вирусом КЧС. После контрольного заражения у поросят через каждые 2 сут в течение 2 нед измеряли температуру тела, отбирали назальные мазки, образцы крови и проводили взвешивание. На 14-е сут после заражения была проведена эвтаназия всех поросят, отбирали образцы селезенки, миндалин и мезентериальных лимфоузлов каждого животного.

Авторы подтверждают, что для опытов было получено разрешение Комитета по этике и гуманному обращению с животными ФГБНУ ФНЦ ВИЭВ РАН и выполнены все требования по работе с животными.

Сыворотки крови исследовали методом ИФА в коммерческих тестсистемах на наличие антител к белку Е2 вируса КЧС (КЧС-СЕРОТЕСТ, «Ветбиохим», Россия) и белку E ${ }^{\text {rns }}$ (Priochek CSFV E ${ }^{\text {rns }}$, «Thermo Fisher Scientific», США) в соответствии с прилагаемыми инструкциями. Для учета результатов реакции использовали планшетный фотометр iMark с фильтром 450 нм («Bio-Rad», CША). Результаты выражали как коэффициент связывания $\left(\mathrm{K}_{\text {св. }}\right)$, который рассчитывали согласно инструкции производителя тестсистемы. Данные интерпретировали (положительная или отрицательная сыворотка) согласно критериям производителя тест-системы. РНК вируса КЧС в назальных смывах и сыворотках выявляли методом полимеразной цепной реакции (ПЦР), используя коммерческую тест-систему для обнаружения вируса классической чумы свиней методом ПЦР («Ветбиохим», Россия); результат учитывали как «+» или «-».

Полученные данные обрабатывали методом дисперсионного анализа (ANOVA). Рассчитывали средние $(M)$ и стандартные ошибки средних $( \pm \mathrm{SEM})$. В разделе «Результаты» различия между показателями для групп I (рекомендованный нами к дальнейшим испытаниям вакцинный препарат) и IX (контроль заражения) статистически значимы при $\mathrm{p} \leq 0,05$.

Результаты. Распределение животных по группам, состав вакцины, содержание антигена и схемы вакцинации описаны в таблице 1.

1. Схема опыта и распределение поросят по группам при сравнении эффективности разных схем применения и вариантов субъединичных вакцин против классической чумы свиней (научно-исследовательская база ФНЦ ВИЭВ РАН «Лисий остров», г. Вышний Волочок)

\begin{tabular}{|c|c|c|c|}
\hline \multirow[b]{2}{*}{ Группа } & \multirow[b]{2}{*}{ Характеристика образца вакцины } & \multicolumn{2}{|r|}{ Число поросят в группе } \\
\hline & & всего & $\begin{array}{l}\text { серопозитивных по анти- } \\
\text { телам к Е2 на дату 1-й или } \\
\text { 1-кратной иммунизации }\end{array}$ \\
\hline & 2-к р ат н ая в а к ци & & \\
\hline I & Белок E2 8Z, 60 мкг, синтетический полиакрилат & 15 & 6 \\
\hline II & Белок E2 8Z 30 мкг, синтетический полиакрилат & 10 & 4 \\
\hline III & Белок E2 8Z, 10 мкг, синтетический полиакрилат & 5 & 2 \\
\hline IV & $\begin{array}{l}\text { Белок Е2 Ши-Мынь + Альфорт-Тюбинген, } 30 \text { мкг, } \\
\text { неполный адъювант Фрейнда }\end{array}$ & 5 & 2 \\
\hline $\mathrm{V}$ & Белок Е2 8Z, 30 мкг, неполный адъювант Фрейнда & 15 & 5 \\
\hline VI & $\begin{array}{l}\text { Коммерческий препарат Е2, } 60 \text { мкг, синтетический } \\
\text { полиакрилат }\end{array}$ & 5 & 0 \\
\hline
\end{tabular}


VII

VIII

IX Контроль заражения (невакцинированные особи,
зараженные в возрасте 84 сут)

X Отрицательный контроль (невакцинированные

и незараженные особи) после 1-й; контрольное заражение осуществляли через 14 сут после повторной вакцинации. При 1-кратной вакцинации ее проводили в возрасте 64 сут, контрольное заражение - через 21 сут после вакцинации.

2. Обобщенные результаты эксперимента по оценке эффективности разных схем применения и вариантов субъединичных вакцин против классической чумы свиней (научно-исследовательская база ФНЦ ВИЭВ РАН «Лисий остров», г. Вышний Волочок)

\begin{tabular}{|c|c|c|c|c|c|}
\hline \multirow[b]{2}{*}{ Группа } & \multirow[b]{2}{*}{ Характеристика образцов вакцины } & \multicolumn{4}{|c|}{ Число поросят } \\
\hline & & зараженных & $\begin{array}{l}\text { с лихорадкой } \\
\text { выше } 41^{\circ} \mathrm{C}\end{array}$ & заболевших & павших \\
\hline $\mathrm{I}(n=15)$ & Белок Е2, 60 мкг, синтетический полиакрилат & 15 & 6 & 0 & 0 \\
\hline II $(n=10)$ & Белок Е2, 30 мкг, синтетический полиакрилат & 10 & 3 & 1 & 0 \\
\hline III $(n=5)$ & Белок Е2, 10 мкг, синтетический полиакрилат & 5 & 5 & 5 & 1 \\
\hline $\mathrm{IV}(n=5)$ & $\begin{array}{l}\text { Белок Е2 Ши-Мынь + Альфорт-Тюбинген, } \\
30 \text { мкг, неполный адъювант Фрейнда }\end{array}$ & 5 & 0 & 0 & 0 \\
\hline $\mathrm{V}(n=15)$ & Белок Е2, 30 мкг, неполный адъювант Фрейнда & 15 & 4 & 2 & 2 \\
\hline VI $(n=5)$ & $\begin{array}{l}\text { Коммерческий препарат E2, } 60 \text { мкг, } \\
\text { синтетический полиакрилат }\end{array}$ & 5 & 3 & 0 & 0 \\
\hline VII $(n=4)$ & $\begin{array}{l}\text { Белок Е2, } 60 \text { мкг, синтетический полиакрилат, } \\
\text { 1-кратная вакцинация }\end{array}$ & 4 & 4 & 4 & 3 \\
\hline VIII $(n=5)$ & $\begin{array}{l}\text { Белок Е2, } 30 \text { мкг, неполный адъювант Фрейнда, } \\
\text { 1-кратная вакцинация }\end{array}$ & 5 & 5 & 1 & 0 \\
\hline $\mathrm{IX}(n=11)$ & $\begin{array}{l}\text { Контроль заражения (невакцинированные } \\
\text { и зараженные особи) }\end{array}$ & 11 & 11 & 11 & 5 \\
\hline $\mathrm{X}(n=8)$ & $\begin{array}{l}\text { Отрицательный контроль (невакцинированные } \\
\text { и незараженные особи) }\end{array}$ & 0 & 0 & 0 & 0 \\
\hline
\end{tabular}

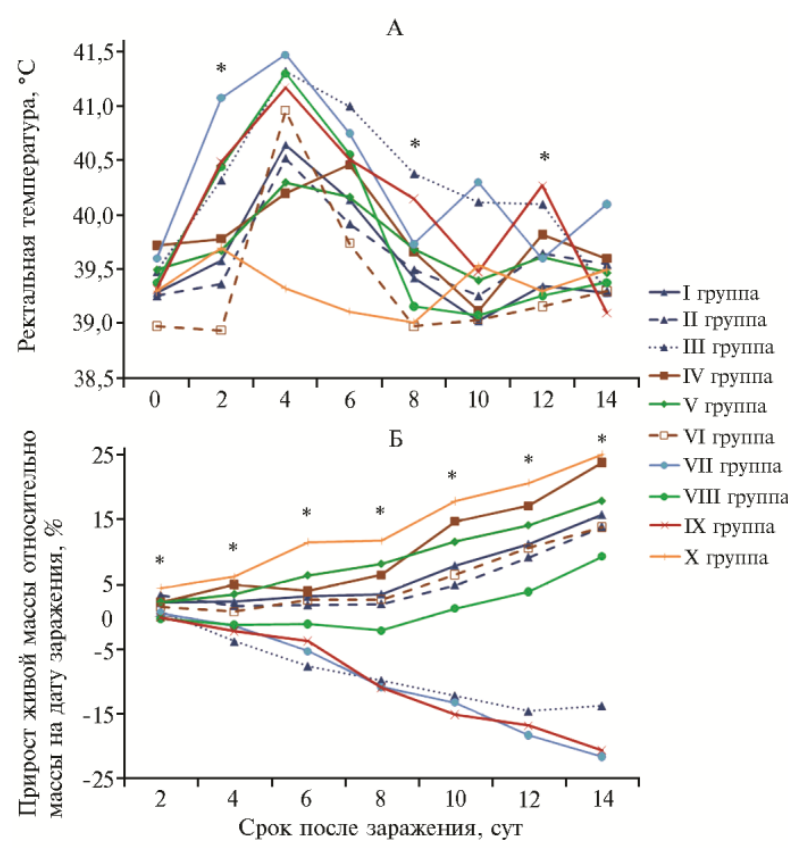

Рис. 1. Ректальная температура (А) и прирост живой массы (Б) у поросят в эксперименте по оценке эффективности разных схем применения и вариантов субъединичных вакцин против классической чумы свиней (научно-исследовательская база ФНЦ ВИЭВ РАН «Лисий остров», г. Вышний Волочок). Описание групп см. в таблице 1, звездочками обозначены точки, для которых различия между I и IX группами статистически значимы при $\mathrm{p}<0,05$.

\section{Результаты экспе-} римента показали (табл. 2), что введение всех образцов вакцины против КЧС не сопровождалось общим угнетением состояния и повышением температуры тела у поросят. Контрольное заражение невакцинированных животных (IX группа)

приводило к развитию типичной клинической картины: на 14-е сут после заражения 5 из 11 поросят в этой группе пали (смертность 45,5\%), у 
остальных наблюдалась значительная потеря живой массы. В III и VII группах смертность составила соответственно 20,0 и 70,0 \%. До 8-х сут после заражения у животных из VIII группы регистировали лихорадку, после чего температура возвращалась к норме. В I, II, IV, V и VI группах происходило умеренное и непродолжительное повышение температуры, и лишь у некоторых животных зафиксировали температуру $41{ }^{\circ} \mathrm{C}$ (рис. 1 , А, см. табл. 2).

Максимальную потерю живой массы наблюдали у поросят из III и VII групп: регистрируемые значения были идентичны таковым в IX группе (контроль заражения) - равномерное снижение показателей отмечали с 1-X по 14-е сут после заражения (см. рис 1, Б). В I, II, IV, V, VI и VIII группах у животных либо не было потери массы, либо она проявлялась в достоверно меньшей степени ( $\leq 0,05)$. Более того, с 4-8-х сут после заражения в I, IV, V и VI группах происходило полное восстановление динамики набора живой массы, характерной для контрольных (неинфицированных) поросят.

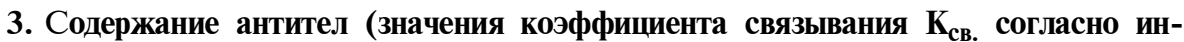
струкциям производителей тест-систем) к вирусным белкам $\mathrm{E}^{\mathrm{rns}}$ и E2 в сыворотках крови поросят в эксперименте по оценке эффективности разных схем применения и вариантов субъединичных вакцин против классической чумы свиней (научно-исследовательская база ФНЦ ВИЭВ РАН «Лисий остров», г. Вышний Волочок)

\begin{tabular}{|c|c|c|c|c|c|c|c|c|}
\hline \multirow{3}{*}{ Группа } & \multirow{3}{*}{$\begin{array}{l}\text { Характеристика } \\
\text { образцов вакцины }\end{array}$} & \multicolumn{2}{|c|}{ Вакцинация } & \multicolumn{2}{|c|}{ Заражение } & \multicolumn{3}{|c|}{ 14-е сут после заражения } \\
\hline & & \multirow{2}{*}{$\begin{array}{l}1-я / \text { един- } \\
\text { ственная }\end{array}$} & \multirow{2}{*}{$2-я$} & \multirow{2}{*}{ E2 } & \multirow{2}{*}{$\mathrm{E}^{\mathrm{rns}}$} & \multirow{2}{*}{ E2 } & \multicolumn{2}{|c|}{$\mathrm{E}^{\mathrm{rns}}$} \\
\hline & & & & & & & $\mathrm{K}_{\mathrm{cB}}$ & «t», \% \\
\hline $\bar{I}$ & $\begin{array}{l}\text { Белок Е2, } 60 \text { мкг, синтети- } \\
\text { ческий полиакрилат }\end{array}$ & $60,72(+)$ & $67,10(+)$ & $104,89(+)$ & $18,59(-)$ & $107,35(+)$ & $47,42(+)$ & 73,3 \\
\hline II & $\begin{array}{l}\text { Белок Е2, } 30 \text { мкг, синтети- } \\
\text { ческий полиакрилат }\end{array}$ & $53,17(+)$ & $57,05(+)$ & $105,29(+)$ & $17,94(-)$ & $108,37(+)$ & $45,95(+)$ & 70,0 \\
\hline III & $\begin{array}{l}\text { Белок Е2, } 10 \text { мкг, синтети- } \\
\text { ческий полиакрилат }\end{array}$ & $70,00(+)$ & $57,90(+)$ & $81,44(+)$ & $23,14(-)$ & $108,40(+)$ & $52,98(+)$ & 80,0 \\
\hline IV & $\begin{array}{l}\text { Белок Е2 Ши-Мынь + Аль- } \\
\text { форт-Тюбинге, } 30 \text { мкг, не- } \\
\text { полный адъювант Фрейнда } \\
\text { Белок Е2, } 30 \text { мкг, непол- }\end{array}$ & $69,66(+)$ & $67,50(+)$ & $71,96(+)$ & $27,88(-)$ & $105,28(+)$ & $50,84(+)$ & 60,0 \\
\hline & ный адъювант Фрейнда & $62,95(+)$ & $71,11(+)$ & $86,51(+)$ & $22,48(-)$ & $103,65(+)$ & $31,88(-)$ & 53,8 \\
\hline VI & $\begin{array}{l}\text { Коммерческий препарат } \\
\text { Е2, } 60 \text { мкг, синтетический } \\
\text { полиакрилат }\end{array}$ & $43,94(-)$ & $40,36(-)$ & $101,78(+)$ & $-0,1$ & $112,26(+)$ & $35,10(-)$ & 60,0 \\
\hline VII & $\begin{array}{l}\text { Белок Е2, } 60 \text { мкг, синтети- } \\
\text { ческий полиакрилат, } \\
\text { 1-кратная вакцинация }\end{array}$ & $62,83(+)$ & н/д & 47,93 (-) & $24,78(-)$ & $107,40(+)$ & $55,70(+)$ & 100 \\
\hline VIII & $\begin{array}{l}\text { Белок Е2, } 30 \text { мкГ, непол- } \\
\text { ный адъювант Фрейнда, } \\
\text { 1-кратная вакцинация }\end{array}$ & $60,26(+)$ & Н/Д & $81,64(+)$ & $25,10(-)$ & $108,84(+)$ & $44,50(+)$ & 60,0 \\
\hline IX & $\begin{array}{l}\text { Контроль заражения (не- } \\
\text { вакцинированные и зара- } \\
\text { женные особи) }\end{array}$ & $51,00(+)$ & $41,15(-)$ & $39,89(-)$ & $14,25(-)$ & $51,07(+)$ & $30,30(-)$ & 33,3 \\
\hline $\mathrm{X}$ & $\begin{array}{l}\text { Отрицательный контроль } \\
\text { (невакцинированные } \\
\text { и незараженные особи) }\end{array}$ & $63,64(+)$ & $50,17(+)$ & $47,58(-)$ & $5,51(-)$ & $41,38(-)$ & $9,70(-)$ & 0 \\
\hline
\end{tabular}

Средние значения относительного содержания антител (коэффициент связывания, $\mathrm{K}_{\text {св. }}$ \%) к белкам Е2 и $\mathrm{E}^{\mathrm{rns}}$ в сыворотках крови поросят представлены в таблице 3. Через 2 нед после второй иммунизации у всех вакцинированных животных обнаружена сероконверсия к белку Е2, в то время как у невакцинированных животных к этому времени статус был серонегативным. После контрольного заражения у вакцинированных животных содержания антител к Е2 продолжало расти. На момент заражения у всех поросят антитела к белку $\mathrm{E}^{\mathrm{rns}}$ не детектировали, однако на 14-е сут 
после заражения их обнаружили у большинства зараженных животных. Минимальная доля положительно реагирующих на $\mathrm{E}^{\mathrm{rns}}$ животных наблюдали в IV, V, VI, VIII группах, а также в группе контроля заражения. Необходимо помнить о том, что вакцинировать следует серонегативных животных (в нашем случае большинство животных достигло этого статуса к 50-суточному возрасту), поскольку высокий уровень материнских антител может негативно влиять на развитие иммунного ответа при вакцинации $(23,24)$.

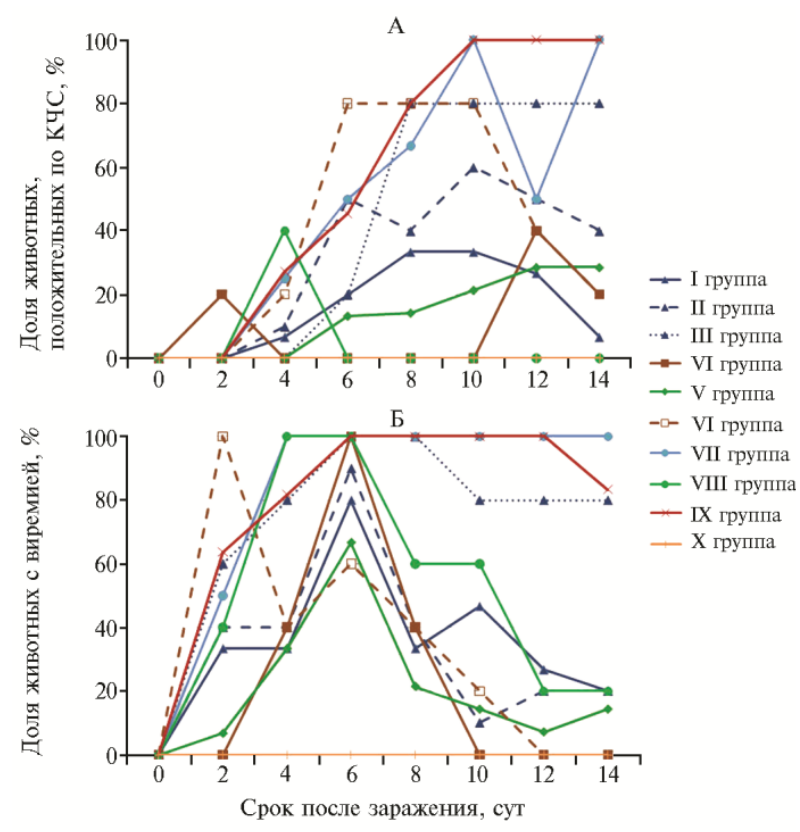

Рис. 2. Выявление РНК вируса классической чумы свиней (КЧС) в назальных смывах (А) и виремия (В) у поросят в эксперименте по оценке эффективности разных схем применения и вариантов субъединичных вакцин против классической чумы свиней (научно-исследовательская база ФНЦ ВИЭВ РАН «Лисий остров», г. Вышний Волочок). ПЦР-анализ; описание групп см. в таблице 1; различия паттернов при выявлении вируса в назальных смывах и в крови животных I и IX групп статистически значимы при $\mathrm{p}<0,05$.

Данные по виремии и выявлению вируса КЧС в назальных мазках после контрольного заражения поросят представлены на рисунке 2. Вакцинные препараты не обеспечивали стерильного иммунитета: ви-

ремия и присутствие вируса КЧС в назальных смывах детектировались во всех экспериментальных группах с наибольшими значениями во II, III и VII, с наименьшими - в I, IV и V (см. рис. 2, А). Примечательно, что данные по выделению вируса положительно коррелируют с клиническими проявлениями КЧС. В сыворотке крови у особей в III, VII и IX группах вирус КЧС выявляли на 6-е и 8-е сут, далее виремию регистрировали не менее чем у 80 \% животных этих групп. В то же время в I, II, IV, V и VI группах пик виремии приходился на 6-е сут, и уже с 8-х сут менее половины животных содержали вирус в крови, после чего доля положительно реагирующих животных продолжала снижаться (см. рис. 2, Б). Известно, что отсутствие стерильного иммунитета характерно как для живых, так и для субъединичных вакцин против КЧС, однако значительное снижение вирусной нагрузки позволяет сделать заключение о высокой эффективности вакцины (25).

Анализ полученных данных показывает, что вакцинные препараты, использованные в I, IV и VI группах, обеспечивали достаточную степень защиты после контрольного заражения. Однако эмульгированный препарат при дозе антигена 30 мкг при хороших результатах в среднем не предотвратил развития заболевания со смертельным исходом у двух поросят. Кроме того, даже 1-кратное применение такого препарата сопровождалось развитием реактогенности (рис. 3, А, Б), что исключает возможность использования таких препаратов в условиях производства. Сравнение эффективности схем с 1- и 2-кратной вакцинации свидетельствует о преимушестве последней, что согласуется с полученными ранее данными 

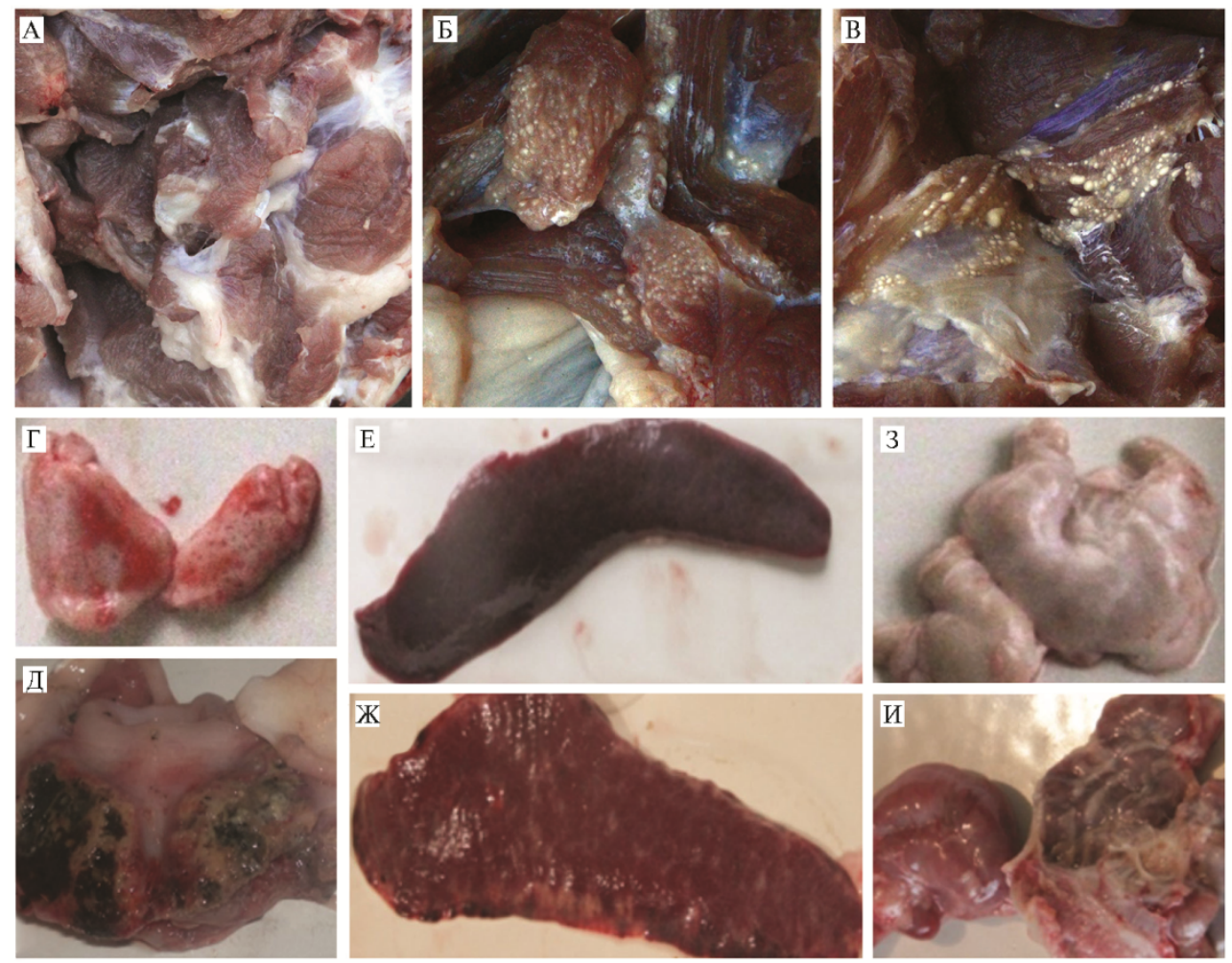

Рис. 3. Реактогенность в ответ на введение вакцинного препарата против классической чумы свиней (КЧС) на основе масляного адъюванта и патологические изменения у поросят при инфекции вирусом КЧС в эксперименте по оценке эффективности разных схем применения и вариантов субъединичных вакцин (научно-исследовательская база ФНЦ ВИЭВ РАН «Лисий остров», г. Вышний Волочок; описание групп см. в таблице 1).

A: Мышечная ткань без изменений, животное из VIII группы.

Б: Мышечная ткань, место введения вакцины, животное из VIII группы. Видны диффузно располагающиеся милиарные узелки белого цвета.

B: Мышечная ткань, место введения вакцины, животное из V группы. Видны диффузно располагающиеся милиарные узелки белого цвета.

Г: Миндалина животного из I группы. Без изменений.

Д: Миндалина животного из IX группы. Эррозивно-язвенное поражение слизистой оболочки с зоной некроза (черного цвета) и ярко выраженной воспалительной реакцией вокруг патологического участка.

E: Селезенка животного из I группы. Упругая консистенция. Края острые.

Ж: Селезенка животного из IX группы. С париетальной и висцеральной поверхности зоны некроза серо-белого цвета, локальные участки кровоизлияний, расположенные в основном по краю органа.

3: Мезентериальный лимфатический узел животного из I группы. Без изменений.

И: Мезентериальный лимфатический узел животного из IX группы. Капсула резко напряжена, на разрезе паренхима с обширными кровоизлияниями.

Некоторые авторы сообщают об эффективности однократного применения рекомбинантной субъединичной вакцины на основе Е2 (27, 28), что может быть связано с удачным выбором адъюванта, введением в состав дополнительных иммуностимулирующих молекул, с использованием полностью наивных к вирусу КЧС поросят.

Отдельно стоит упомянуть о необходимости включения в состав вакцины белков Е2 обоих генотипов (IV группа). Лишь один из четырех антигенных эпитопов Е2 консервативен у основных генотипов вКЧС (1, 29, 30), что может приводить к сниженной эффективности рекомбинатной вакцины при заражении гетерологичными штаммами вКЧС (31). С учетом 
того, что на территории России показана циркуляция генотипов вКЧС 1 (исторические) и 2 (32, 33), необходимость включения в состав вакцины рекомбинантных белков Е2 обоих генотипов вКЧС не вызывает сомнений. Проведенные нами исследования показали, что такая вакцина по эффективности не уступает препарату на основе Е2 генотипа 1 вКЧС. Однако использованный при изготовлении этого препарата масляный адъювант вызывал реактогенность, поэтому в дальнейшем необходимо провести сравнение эффективности препаратов на основе синтетического полиакрилата, в том числе при заражении животных штаммами-пробойниками вКЧС разных генотипов.

Таким образом, в результате проведенных исследований установлен препарат на основе рекомбинантной вакцины против классической чумы свиней (КЧС), сочетающий безвредность и высокую эффективность. Двукратная иммунизация вакциной, содержащей Е2 (60 мкг/доза) штамма 8Z генотипа 1 вКЧС, с использованием синтетического полиакрилата в качестве адъюванта обеспечивала выраженный гуморальный иммунный ответ с высокой степенью защиты от клинических проявлений КЧС и не сопровождалась проявлением реактогенности. Использование рекомбинантной вакцины против КЧС позволило дифференцировать вакцинированных и инфицированных животных.

\footnotetext{
1000 «ветбиохим»,

105120 Россия, г. Москва, 3-й Сыромятнический пер., 3/9, стр. 2, e-mail: kkendwell@mail.ru $₫$, raevsergey@mail.ru, anton_oskol@mail.ru, shemelkov@mail.ru, oleglat80@mail.ru, olesenka80@mail.ru, lvkostina@mail.ru, tsibezov@yandex.ru, kkunakov@yandex.ru, aliper@narvac.com;

2ФГБНУ ФНЦ Всероссийский НИИ экспериментальной ветеринарии им. К.И. Скрябина и Я.Р. Коваленко РАН, 109428 Россия, г. Москва, Рязанский просп., 24, к. 1,

e-mail: Stafford.v.v@gmail.com, zaberezhny@mail.ru;

${ }^{3}$ АНО НИИ диагностики и профилактики болезней человека и животных,

123098 Россия, г. Москва, ул. Гамалеи, 16, стр. 2,

e-mail: info@dpri.ru
}

Sel'skokhozyaistvennaya biologiya [Agricultural Biology], 2019, V. 54, № 6, pp. 1236-1246

\title{
EXPERIMENTAL SUBUNIT VACCINE AGAINST CLASSICAL SWINE FEVER DEVELOPMENT AND TRIAL
}

\author{
K.P. Alekseev', S.A. Raev', A.G. Yuzhakov', E.V. Shemelkov', O.E. Latyshev', \\ O.V. Eliseeval, L.V. Kostina', V.V. Tsibezov', V.V. Stafford ${ }^{2}$, K.Yu. Kunakov', \\ O.A. Verkhovsky ${ }^{3}$, A.D. Zaberezhny', T.I. Aliper ${ }^{1}$
}

\begin{abstract}
${ }^{1}$ LLC Vetbiochem, 3/9-2, 3-i Syromyatnicheskii per., Moscow, 105120 Russia, e-mail kkendwell@mail.ru (凹 corresponding author), raevsergey@mail.ru, anton_oskol@mail.ru, shemelkov@mail.ru oleglat80@mail.ru, olesenka80@mail.ru, lvkostina@mail.ru, tsibezov@yandex.ru, kkunakov@yandex.ru, aliper@narvac.com;

${ }^{2}$ Federal Scientific Centre VIEV, 24-1, Ryazanskii prosp., Moscow, 109428 Russia, e-mail Stafford.v.v@gmail.com, zaberezhny@mail.ru;

${ }^{3}$ ANO Diagnostic and Prevention Research Institute for Human and Animal Diseases, 16, ul. Gamaleya, Moscow, 123098 Russia, e-mail info@dpri.ru

ORCID:

Alekseev K.P. orcid.org/0000-0001-9536-3127

Raev S.A. orcid.org/0000-0002-8823-2513

Yuzhakov A.G. orcid.org/0000-0002-0426-9678

Shemelkov E.V. orcid.org/0000-0002-9485-2196

Latyshev O.E. orcid.org/0000-0002-5757-3809

Eliseeva O.V. orcid.org/0000-0002-0723-9749

Tsibezov V.V. orcid.org/0000-0003-2150-5764 Stafford V.V. orcid.org/0000-0001-8725-2320

Kunakov K.Yu. orcid.org/0000-0001-7745-6899

Verkhovsky O.A. orcid.org/0000-0003-0784-9341

Zaberezhny A.D. orcid.org/0000-0001-7635-2596

Aliper T.I. orcid.org/0000-0003-2696-1363
\end{abstract}

Kostina L.V. orcid.org/0000-0002-9556-1454

The authors declare no conflict of interests

Received July 16, 2019

doi: 10.15389/agrobiology.2019.6.1236eng

Abstract

Classical swine fever (CSF), the highly contagious viral disease, remains the major threat to 
pork industry in top ten pork producing countries save the United States. Disease outbreaks and following restrictions in international trade are causing major economic losses worldwide. Wild boars are the natural reservoir of the virus. They represent high danger to pork industry in regions with high density of wild boar population. Live attenuated vaccine has been used in Russia for decades for the total swine population vaccination. Today Russia belongs to world leaders in the pork production, but it still has to be recognized as CSF virus (CSFV) free country (or region) to be incorporated in a global market. The first step in this direction would be the implementation of nonreplicating marker vaccines, allowing the differentiation between infected and vaccinated animals (DIVA). Here we first report results of recombinant E2 protein-based vaccine formulations trial in Russian Federation, where optimal administration protocol, adjuvant, dosage of specific component were selected. From the formulations tested, safe and effective vaccine formulation was selected, that needs to be tested for antigen stability and immunity duration in vaccinated animals, and then undergo clinical trial on farm. The aim of our study is the development of the vaccine based on CSFV recombinant surface glycoprotein E2 according to requirements for the country/region free of CSFV. We performed the series of animal trials on Sus scrofa landrace-duroc breed (total number of pigs 84 , divided into 9 experimental and 2 control groups) to assess the vaccination schedule, antigen dosage, and choice of adjuvant. Highly pathogenic CSFV Shi-Men strain was used for challenge in $5 \times 10^{5}$ $\mathrm{LD}_{50}$ dose (ARRIAH collection). Double shot introduction of $10 \mu \mathrm{g}$ or $30 \mu \mathrm{g}$ of antigen as well as single shot with 30 or $60 \mu \mathrm{g}$ of E2 had not provided sufficient level of protection. Oil adjuvant was reactogenic at the inoculation spot even when used once, while polymeric adjuvant has not produced local or systemic reactions after the administration single time or twice. Double administration with the vaccine containing $60 \mathrm{rg}$ of the antigen and polymeric adjuvant has completely protected pigs from the death after the challenge, while in non-vaccinated/challenged control group 5 out of 11 animals died within 14 days post-challenge. Vaccinated animals had less pronounced fever that lasted shorter (rise of the rectal temperature was delayed for 2 days, release of fever 2 days before the control challenge group), frequency and longevity of viremia and virus shedding in nasal swabs were significantly $(\mathrm{p} \leq 0.05)$ reduced as compared to inoculated control piglets. Animals in this vaccinated group gained weight every day after the challenge, being slightly behind non-vaccinated/non-challenged controls. The high levels of antibodies against E2 protein were detected in sera of vaccinated animals before the challenge and they all were negative for antibodies to $E^{\text {rns }}$ protein. After the challenge antibodies to $E^{\text {rns }}$ proteins started to raise in sera of all animals save non-vaccinated/non-challenged controls, thus we developed the product that may be implemented as a marker vaccine against CSFV.

Keywords: Classical swine fever, subunit vaccine, CSF E2, adjuvant, vaccine development.

\section{R E F E R E N C ES}

1. Chander V., Nandi S., Ravishankar C., Upmanyu V., Verma R. Classical swine fever in pigs: recent developments and future perspectives. Animal Health Research Reviews, 2014, 15(1): 87 101 (doi: 10.1017/S1466252314000024).

2. Beltran-Alcrudo D., Falco J.R., Raizman E., Dietze K. Transboundary spread of pig diseases: the role of international trade and travel. BMC Veterinary Research, 2019, 15(1): 64 (doi: 10.1186/s12917-019-1800-5).

3. Zhou B. Classical swine fever in China - an update minireview. Frontiers in Veterinary Science, 2019, 6: 187 (doi: 10.3389/fvets.2019.00187).

4. Sergeev V.A., Orlyankin B.G., Alekseev K.P., Zaberezhnyi A.D., Aliper T.I., Nepoklonov E.A. Veterinariya, 2018, 4: 3-11.

5. Kirkland P.D., Le Potier M.-F., Vannier P., Finlaison D. Pestiviruses. In: Diseases of swine. J.J. Zimmerman, L.A. Karriker, A. Ramirez, K.J. Schwartz, G.W. Stevenson (eds.). WileyBlackwell, 2012: 538-553.

6. Rümenapf T., Meyers G., Stark R., Thiel H.J. Molecular characterization of hog cholera virus. In: Ruminant Pestivirus infections. Archives of Virology (Supplementum 3), vol. 3. B. Liess, V. Moennig, J. Pohlenz, G. Trautwein (eds.). Springer, Vienna, 1991: 7-18 (doi: 10.1007/978-3-7091-9153-8_2).

7. Lindenbach B.D., Muttay C.L., Thiel H.J. Flaviviridae. In: Fields virology. D.M. Knipe, P.M. Howley (eds.). Lippincott Williams and Wilkins, Philadelphia, 2013: 712-746.

8. Thiel H.J., Stark R., Weiland E., Rümenapf T., Meyers G. Hog cholera virus: molecular composition of virions from a pestivirus. Journal of Virology, 1991, 65: 4705-4712.

9. Wang F.I., Deng M.C., Huang Y.L., Chang C.Y. Structures and Functions of Pestivirus Glycoproteins: Not Simply Surface Matters. Viruses, 2015, 7(7): 3506-3529 (doi: 10.3390/v7072783)

10. Weiland E., Stark R., Haas B., Rьmenapf T., Meyers G., Thiel H.J. Pestivirus glycoprotein which induces neutralizing antibodies forms part of a disulfide-linked heterodimer. Journal of Virology, 1990, 64(8): 3563-3569.

11. Nepoklonov E.A., Aliper T.I., Leneva I.A. Voprosy virusologii, 1999, 2: 54-60 (in Russ.).

12. Chang C.Y., Huang C.C., Lin Y.J., Deng M.C., Chen H.C., Tsai C.H., Chang W.M., Wang F.I. Antigenic domains analysis of classical swine fever virus E2 glycoprotein by mutagenesis and conformation-dependent monoclonal antibodies. Virus Research, 2010, 149(2): 183-189 
(doi: 10.1016/j.virusres.2010.01.016).

13. Schroeder S., von Rosen T., Blome S., Loeffen W., Haegeman A., Koenen F., Uttenthal A. Evaluation of classical swine fever virus antibody detection assays with an emphasis on the differentiation of infected from vaccinated animals. Revue Scientifique et Technique (International Office of Epizootics), 2012, 31(3): 997-1010 (doi: 10.20506/rst.31.3.2173).

14. Nepoklonov E.A. Klassicheskaya chuma svinei: razrabotka metodov laboratornoi diagnostiki $i$ sredstv spetsificheskoi profilaktiki. Doktorskaya dissertatsiya [Classical swine fever: the development of laboratory diagnostic methods and means of specific prevention. DSc Thesis]. Moscow, 2000 (in Russ.).

15. Blome S., Mos C., Reimann I., König P., Beer M. Classical swine fever vaccines - State-ofthe-art. Veterinary Microbiology, 2017, 206: 10-20 (doi: 10.1016/j.vetmic.2017.01.001).

16. Larson K.L., Zaabel P., Spickler A.R., Roth J.A. NAHEMS Guidelines: Vaccination for Contagious Diseases, Appendix B: Vaccination for Classical Swine Fever. USDA, 2017.

17. Hulst M.M., Westra D.F., Wensvoort G., Moormann R.J. Glycoprotein E1 of hog cholera virus expressed in insect cells protects swine from hog cholera. Journal of Virology, 1993, 67: 5435-5442.

18. König M., Lengsfeld T., Pauly T., Stark R., Thiel H.-J. Classical swine fevervirus: independent induction of protective immunity by two structural glycoproteins. Journal of Virology, 1995, 69: 6479-6486.

19. Huang Y.-L., Denga M.-C., Fun-In Wang F.-I., Huang C.-C., Chang C.-Y. The challenges of classical swine fever control: Modified live and E2 subunit vaccines. Virus Research, 2014, 179: 1-11 (doi: 10.1016/j.virusres.2013.10.025).

20. Dong X.N., Chen Y.H. Marker vaccine strategies and candidate CSFV marker vaccines. Vaccine, 2007, 25(2): 205-230 (doi: 10.1016/j.vaccine.2006.07.033).

21. Krivonos A.V., Zaberezhnyi A.D., Grebennikova T.V., Aliper T.I., Musienko M.I., Gibadulin R.A., Tsibezov V.V., Bogdanova V.S., Kal'nov S.L., Aliper T.I., Nepoklonov E.A. Voprosy virusologii, 2000, 2: 29-36 (in Russ.).

22. Tsibezov V.V., Bogdanova V.S., Zaberezhnyi A.D., Grebennikova T.V., Krivonos A.V., Dudnikov L.A., Kal'nov S.L., Aliper T.I., Nepoklonov E.A. Voprosy virusologii, 2000, 2: 36-41 (in Russ.).

23. Klinkenberg D., Moormann R.J.M., de Smit A.J., Bouma A., de Jong M.C.M. Influence of maternal antibodies on efficacy of a subunit vaccine: transmission of classical swine fever virus between pigs vaccinated at 2 weeks of age. Vaccine, 2002, 20: 3005-3013 (doi: 10.1016/S0042207X(02)00283-X).

24. Lipowski A., Drexler C., Pejsak Z. Safety and efficacy of a classical swine fever subunit vaccine in pregnant sows and their offspring. Veterinary Microbiology, 2000, 77(1-2): 99-108 (doi: 10.1016/S0378-1135(00)00266-2).

25. van Oirschot J.T. Vaccinology of classical swine fever: from lab to field. Veterinary Microbiology, 2003, 96(4): 367-384 (doi: 10.1016/j.vetmic.2003.09.008).

26. Bouma A., de Smit A.J., de Kluijver E.P., Terpstra C., Moormann R.J. Efficacy and stability of a subunit vaccine based on glycoprotein E2 of classical swine fever virus. Veterinary Microbiology, 1999, 66(2): 101-114 (doi: 10.1016/S0378-1135(99)00003-6).

27. Madera R., Gong W., Wang L., Burakova Y., Lleellish K., Galliher-Beckley A., Nietfeld J., Henningson J., Jia K., Li P., Bai J., Schlup J., McVey S., Tu C., Shi J. Pigs immunized with a novel E2 subunit vaccine are protected from subgenotype heterologous classical swine fever virus challenge. BMC Veterinary Research, 2016, 12(1): 197 (doi: 10.1186/s12917-016-0823-4).

28. Suárez M., Sordo Y., Prieto Y., Rodríguez M.P., Méndez L., Rodríguez E.M., RodríguezMallon A., Lorenzo E., Santana E., González N., Naranjo P., Frías M.T., Carpio Y., Estrada M.P. A single dose of the novel chimeric subunit vaccine E2-CD154 confers early full protection against classical swine fever virus. Vaccine, 2017, 35(34): 4437-4443 (doi: 10.1016/j.vaccine.2017.05.028).

29. van Rijn P.A., Miedema G.K., Wensvoort G., van Gennip H.G., Moormann R.J. Antigenic structure of envelope glycoprotein E1 of hog cholera virus. Journal of Virology, 1994, 68(6): 3934-3942.

30. Yu M., Wang L.F., Shiell B.J., Morrissy C.J., Westbury H.A. Fine mapping of a C-terminal linear epitope highly conserved among the major envelope glycoprotein E2 (gp51 to gp54) of different pestiviruses. Virology, 1996, 222(1): 289-292 (doi: 10.1006/viro.1996.0423).

31. Huang Y.L., Deng M.C., Wang F.I., Huang C.C., Chang C.Y. The challenges of classical swine fever control: modified live and E2 subunit vaccines. Virus Research, 2014, 179: 1-11 (doi: 10.1016/j.virusres.2013.10.025).

32. Vlasova A., Grebennikova T., Zaberezhny A., Greiser-Wilke I., Floegel-Niesmann G., Kurinnov V., Aliper T., Nepoklonov E. Molecular epidemiology of classical swine fever in the Russian Federation. Journal of Veterinary Medicine and Infectious Disease Veterinary Public Health, 2003, 50(8): 363-367 (doi: 10.1046/j.1439-0450.2003.00695.x).

33. Titov I., Tsybanov S., Malogolovkin A. Genotyping of classical swine fever virus using highresolution melt analysis. Journal of Virological Methods, 2015, 224: 53-57 (doi: 10.1016/j.jviromet.2015.08.012). 